\title{
Phenylethynylbenzyl-Modified Biguanides Inhibit Pancreatic Cancer Tumor
}

\section{Growth}

Audrey Hébert ${ }^{[\mathrm{a}] *}$, Maxime Parisotto ${ }^{[\mathrm{a}] *}$, Marie-Camille Rowell ${ }^{[\mathrm{b}]}$, Alexandra Doré ${ }^{[\mathrm{a}]}$, Ana Fernandez ${ }^{[\mathrm{b}]}$, Guillaume Lefrancois $^{[\mathrm{a}]}$, Paloma Kalegari ${ }^{[\mathrm{b}],}$ Gerardo Ferbeyre ${ }^{[\mathrm{b}]}$ and Andreea R. Schmitzer*[a]

${ }^{[a]}$ Département de Chimie - Faculté des Arts et des Sciences, Université de Montréal, 2900 Edouard Montpetit, CP 6128 Succursale Centre-Ville, Montréal, H3C3J7, Québec, Canada. ${ }^{[b]}$ Département de Biochimie et Médecine Moléculaire - Faculté de Médecine, Université de Montréal.

"Contributed equally to this work

Corresponding author: *ar.schmitzer@umontreal.ca or g.ferbeyre@umontreal.ca 


\begin{abstract}
We present the design and synthesis of a small library of substituted biguanidium salts and their capacity to inhibit the growth/viability of pancreatic cancer cells. We first present their in vitro and membrane activity, before we address their mechanism of action in living cells and in vivo activity. We show that phenylethynyl biguanidium salts possess higher ability to cross hydrophobic barriers, improved mitochondrial accumulation and anticancer activity. Mechanistically, the most active compound 1b, like metformin, decreases the $\mathrm{NAD}^{+} / \mathrm{NADH}$ ratio and mitochondrial respiration, but at 800 -fold lower concentration. In vivo studies with, the most active, compound $\mathbf{1 b}$ show a significant growth inhibition of pancreatic cancer xenografts in mice, while biguanides currently in clinical trials had no activity.
\end{abstract}

Keywords: biguanidium salts; pancreatic cancer; antiproliferative properties

\title{
Introduction
}

Although they have been used for decades in the treatment of type II diabetes, it is only quite recently that biguanides have been found to have interesting anticancer properties ${ }^{1}$. Many epidemiological studies have linked the long-term regular intake of metformin (1,1-dimethylbiguanide), a commonly used antidiabetic biguanide, to the reduction of the incidence of a variety of cancers in diabetic patients ${ }^{2}$. These results suggest that biguanides have anticancer activity, an idea that was experimentally verified using cancer models in cell culture and mice ${ }^{3}$. However, several clinical trials featuring metformin as a chemotherapeutic agent in humans have been unsuccessful ${ }^{4-6}$. One of the 
reasons brought forward to explain this failure is the high hydrophilicity of metformin, administrated as a monoprotonated chloride salt at physiological $\mathrm{pH}(\mathrm{pKa} 2.8$ and 11.5). While animal models were given very high quantities of metformin to observe a potent anticancer activity ${ }^{7}$, the antidiabetic doses used in human patients were deemed too low to attain the reported antiproliferative concentration of $5 \mathrm{mM}$ in vitro ${ }^{8-9}$.

Even if the molecular target of biguanides has not been identified yet, it is obvious that membrane insertion and mitochondrial penetration are critical for their activity. Different metformin analogues with lipophilic substituents and improved cellular penetration were previously reported. Narise et al. proposed in 2014 a series of phenformin derivatives possessing various substituents on the phenyl ring and bioisosteric replacements of the biguanide unit ${ }^{10}$. Neuzil et al. showed that biguanides functionalized with a mitochondria-targeting moiety such as triphenylphosphonium $\left(\mathrm{TPP}^{+}\right)$, possess anticancer activities up to a 800 -fold higher than metformin ${ }^{11}$. In agreement, it has been shown that metformin exert its anti-cancer activity at least in part by perturbing mitochondrial respiration ${ }^{7,12}$.

We have actively investigated the membrane perturbation properties of synthetic amphiphilic cationic ion transporters and antibiotics, including derivatives of phenylethynylbenzyl (PEB) - disubstituted imidazolium and benzimidazolium salts. We have demonstrated that the activities of these organic salts in artificial phospholipid bilayers or living prokaryotic and eukaryotic cells were the results of membrane penetration, self-assembly and partition ${ }^{13}$. Since all the studied organic salts containing a PEB unit in their structure were active on bacterial membranes and that mitochondria are essentially ancient bacteria trapped in eukaryotic cells, we reasoned that conjugating 
biguanides with the PEB unit could improve metformin's cellular/mitochondrial uptake. We generated a small library of PEB-substituted biguanidium salts and their hydrogenated analogues and studied the capacity of these compounds to affect the growth/viability of pancreatic cancer cells. We identified a novel class of biguanide compounds with better membrane crossing abilities and more potent anticancer activity than metformin and phenformin.

\section{Results and Discussion}

Phenylethynylbenzyl (PEB) - disubstituted imidazolium and benzimidazolium were shown to self-assemble inside phospholipid membranes and form stable channels through $\pi-\pi$ interactions (Figure 1A $)^{13}$. The transport of protons and ions through these open channels induced membrane perturbation, depolarization and bacterial death. Even if the PEB -disubstituted benzimidazolium salts were very active on bacterial membranes, their potential as mitochondrial membrane perturbators was not further explored because of their high toxicity on red blood cells $\left(\mathrm{HC}_{50} \text { at } 0.15 \mathrm{mM}\right)^{13-14}$. The replacement of one PEB unit with a phenyl or a methyl group resulted in less toxic compounds $\left(\mathrm{HC}_{50}\right.$ at $1 \mathrm{mM}$ for the benzyl and $150 \mathrm{mM}$ for the methyl substituent), forming more compact aggregates in the membranes. 
A.
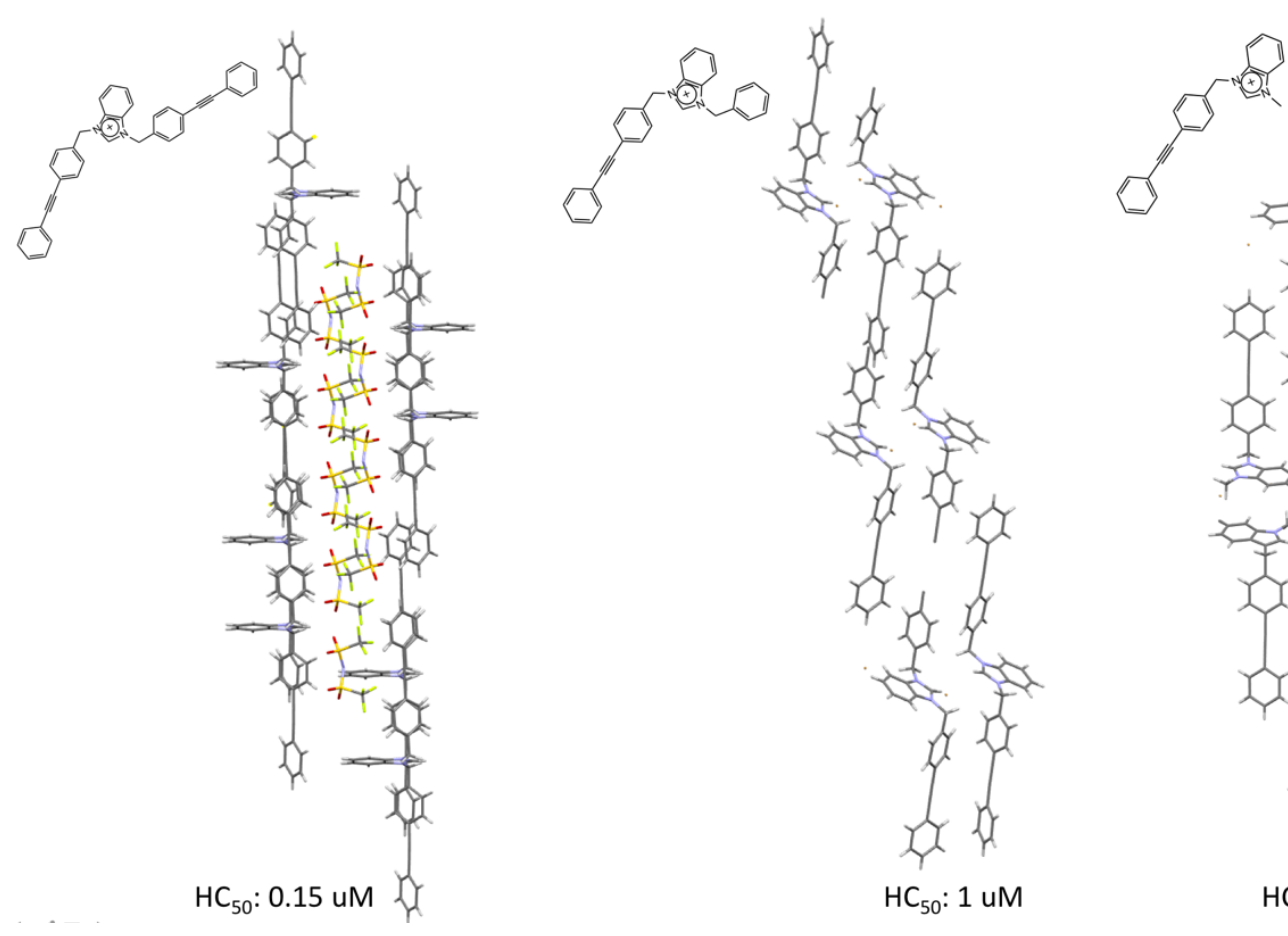

$\mathrm{HC}_{50}: 1 \mathrm{uM}$
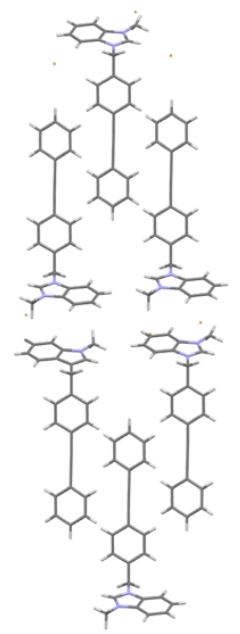

$\mathrm{HC}_{50}: 150 \mathrm{uM}$

B.

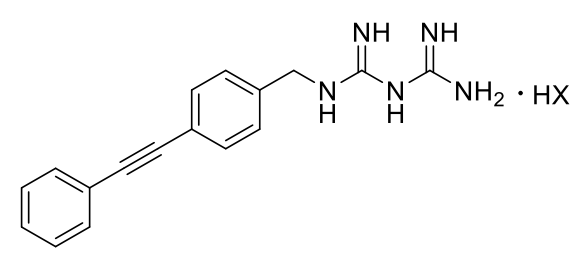

1

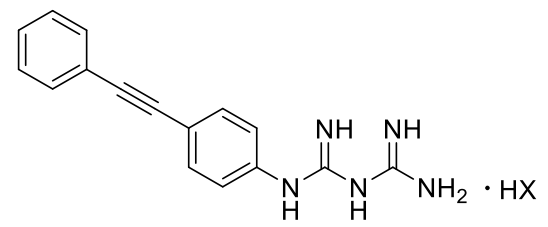

3<smiles>[X][X]C(=N)NC(=N)NCc1ccc(CCc2ccccc2)cc1</smiles>

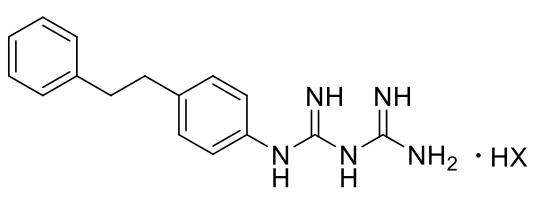

4

$$
X=\operatorname{NTf}_{2}(\mathbf{a}), \operatorname{OTf}(\mathbf{b}), \mathrm{Cl}(\mathbf{c})
$$


bioRxiv preprint dol: https://doi.org/10.1101/793109; this version posted October 7, 2019. The copyright holder for this preprint (which was not certified by peer review) is the author/funder. All rights reserved. No reuse allowed without permission.

C.
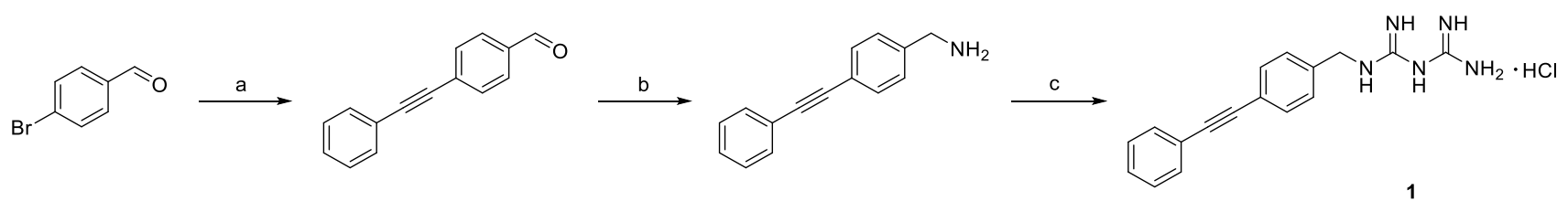

d

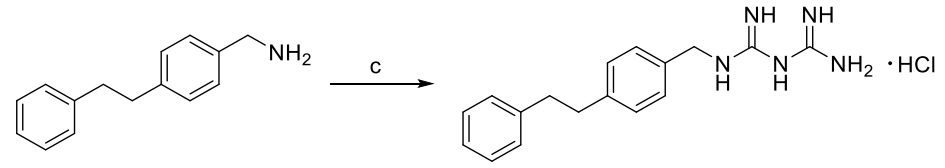

2

D.
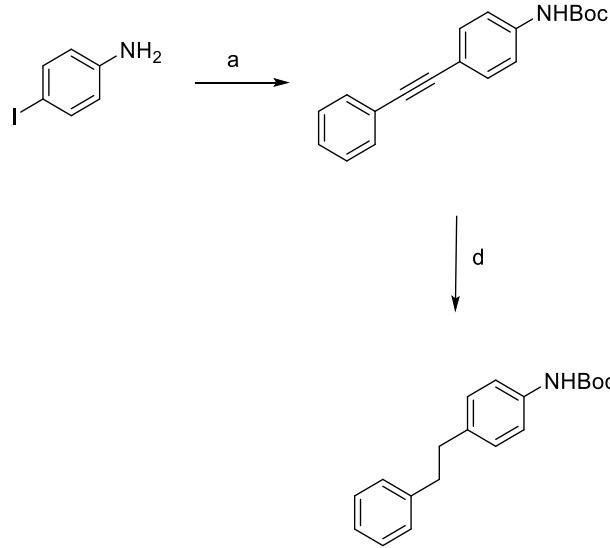
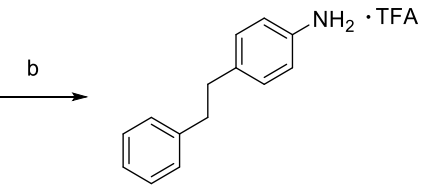
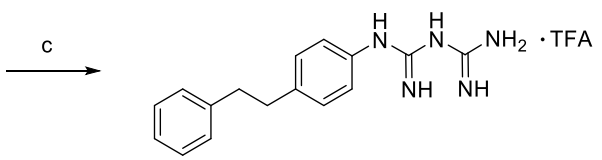

4 
E.

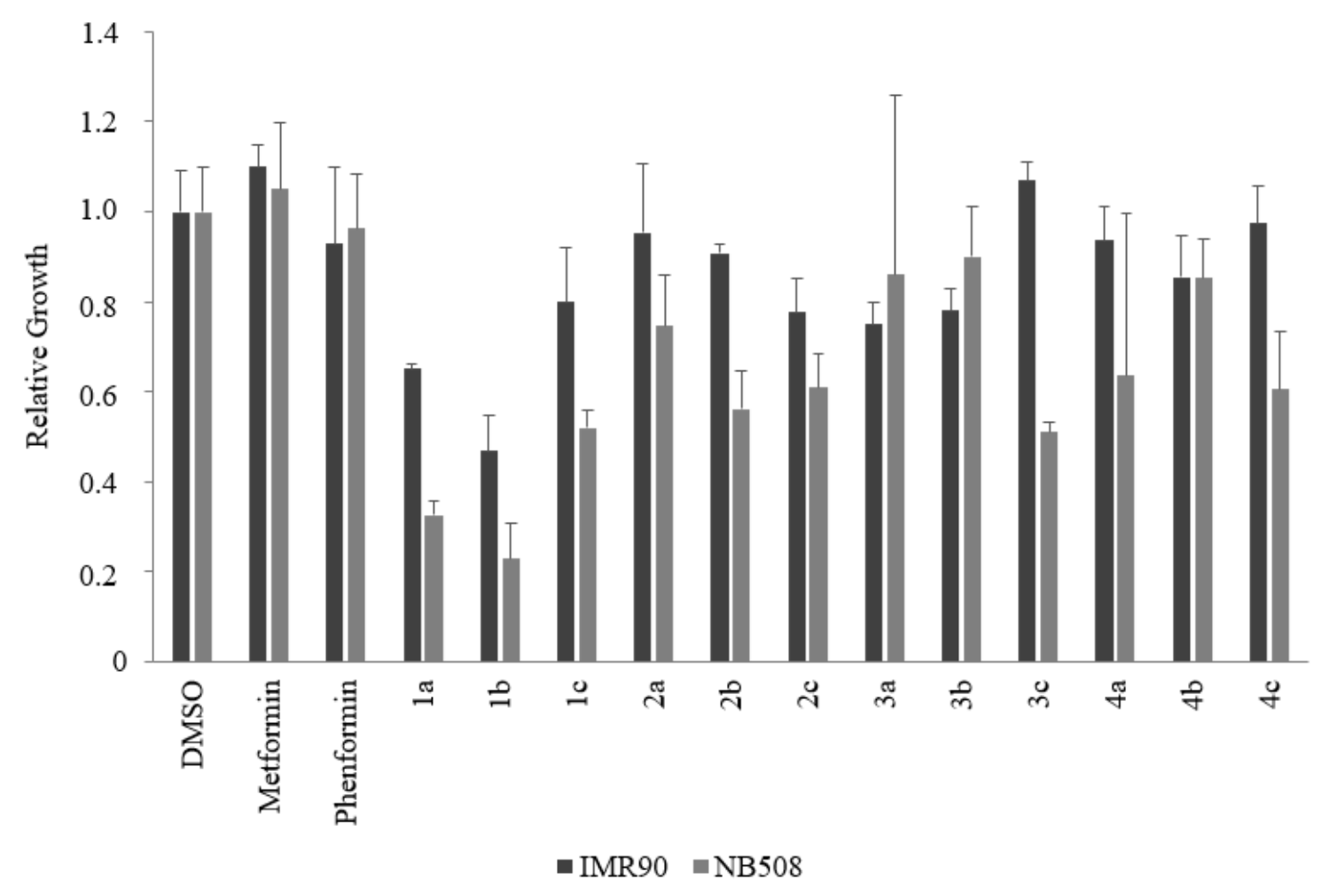

F.
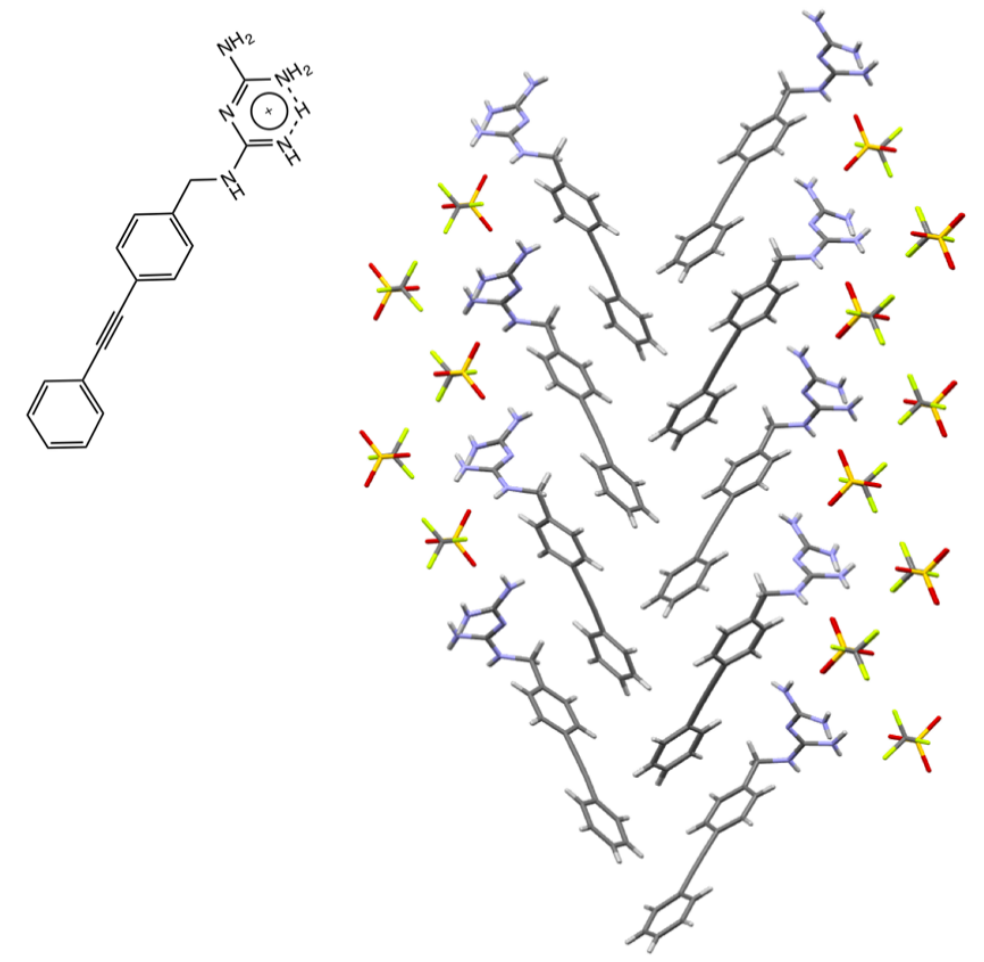
Figure 1: A) Structure of previously studied PEB-substituted benzimidazolium salts ${ }^{13}$ B) Structure of PEB-substituted biguanidium salts. C) Synthesis of 4(phenylethynyl)benzylbiguanide 1 and 4-(phenylethy)benzylbiguanide 2 (a) Phenylacetylene, $\mathrm{PdCl}_{2} \mathrm{PPH}_{3}, \mathrm{CuI}, \mathrm{PPH}_{3}, \mathrm{Et}_{3} \mathrm{~N}$, THF, $70^{\circ} \mathrm{C}$, o.n. (b) $\mathrm{NaCN}\left(\mathrm{BH}_{3}\right)_{3}$, $\mathrm{EtOH}_{\mathrm{NH} 4 \mathrm{OAc} \text { sat. }} / \mathrm{NH}_{3}, 80^{\circ} \mathrm{C}$, o.n (c) Dicyandiamide, $\mathrm{TMSCl}, \mathrm{THF}_{\text {anh. }}, 145^{\circ} \mathrm{C}, 1 \mathrm{~h}$ (d) $\mathrm{Pd} / \mathrm{C}$ $10 \%, \mathrm{H}_{2}, \mathrm{EtOH} / \mathrm{AcOEt}, 60^{\circ} \mathrm{C}, 2 \mathrm{~h}$. D) Synthesis of 4-(phenylethynylphenyl)biguanidium 3 and 4-(phenylethylphenyl)biguanidium 4 (a) 1) $\mathrm{Boc}_{2} \mathrm{O}$, THF, 2h, 2) Phenylacetylene, $\mathrm{PdCl}_{2} \mathrm{PPH}_{3}, \mathrm{CuI}, \mathrm{PPH}_{3}, \mathrm{Et}_{3} \mathrm{~N}, \mathrm{THF}, 70^{\circ}$, o.n. (b) TFA, DCM, $60^{\circ} \mathrm{C}, 2 \mathrm{~h}$ (c) Dicyandiamide, TMSCl, $\mathrm{THF}_{\text {anh. }}, 145^{\circ} \mathrm{C}, 1 \mathrm{~h}$ (d) $\mathrm{Pd} / \mathrm{C} 10 \%, \mathrm{H}_{2}, \mathrm{EtOH} / \mathrm{AcOEt}, 60^{\circ} \mathrm{C}, 2 \mathrm{~h}$. E) Relative growth of NB508 mouse pancreatic ductal adenocarcinoma cells and IMR90 fibroblasts exposed to $5 \mu \mathrm{M}$ of PEB-biguanidium. Cells were incubated for $72 \mathrm{~h}$ at $37^{\circ} \mathrm{C}$. F) Crystal structure of $\mathbf{1 b}$ showing its self-assembly in the solid state.

\section{Synthesis}

PEB-Biguanidium chloride 1c was synthesised by the cross-coupling of 4bromobenzaldehyde with phenylacetylene followed by the reductive amination of the aldehyde with $\mathrm{NaCNBH}_{3}$. The biguanide was then formed by reacting the amine with dicyandiamide to afford PEB-biguanidium chloride 1c with $30 \%$ yield. PEB-biguanidium chloride 2c was obtained by hydrogenation of 4-(phenylethynyl)benzyl amine followed by the formation of the biguanidium chloride with $20 \%$ yield (Figure 1C). 
PEB-biguanidium 3 was synthesized by the cross-coupling of BOC protected 4iodoaniline with phenylacetylene followed by the deprotection of the amine and the formation of the biguanidium trifluoroacetate with dicyandiamide in a 24\% yield. PEBbiguanidium 4 was synthesized by the hydrogenation of tert-butyl-(4(phenylethynyl)phenyl)carbamate, deprotection of the amine and formation of the biguanidium trifluoroacetate with a 35\% yield (Figure 1D).

The counter-anions of PEB-Biguanidium chloride 1c and 2c were exchanged through the anion metastasis of chloride with either $\operatorname{LiNTf}_{2}(\mathbf{a})$ or $\operatorname{LiOTf}(\mathbf{b})$ in methanol in quantitative yield. The counter-anions of PEB-biguanidium 3 and $\mathbf{4}$ were exchanged by the same procedure with the addition of a deprotonation step with $\mathrm{NaHCO}_{3}$ before the ion exchange step.

\section{In vitro screening}

The biguanidium salts possessing various counter-anions were first screened for the growth inhibition of mouse pancreatic ductal adenocarcinoma cells NB508 and normal human fibroblasts IMR90 (Figure 1E), at $5 \mu \mathrm{M}$. Almost all the tested compounds were able to inhibit the growth of cancer cells at this concentration, while no effect was observed for metformin and phenformin at the same concentration. The most important antiproliferative activities were observed for $\mathbf{1 a}$ and $\mathbf{1 b}$, both showing a good selectivity towards the cancer cells.

The toxicity of PEB-Biguanidiums salts was estimated through their hemolytic activity by incubating red blood cells (RBC) with the compounds for 1 hour (See 
supporting information). A very low hemolytic activity (under 10\%) was observed for all the compounds, even at concentrations up to $150 \mu \mathrm{M}$. As RBC are mainly composed of a plasma membrane enveloping hemoglobin, the low hemolysis observed indicates that PEB-Biguanidium salts are not disrupting RBC's membranes, compared to the previously reported benzimidazolium salts ${ }^{15-16}$.

\section{Membrane activity}

As compounds 1a-c showed good inhibition of the growth of cancer cells and low activity on fibroblasts, they were retained for further investigation. Compound $\mathbf{1 b}$ was the only one with good methanol and DMSO solubility even at high concentrations, and was used for further investigation. The $\log \mathrm{P}$ of compound $\mathbf{1 b}(0.4)$ is much higher than metformin $(-1.4)^{17}$ and phenformin $(-0.8)^{18}$, indicating its higher hydrophobicity and higher membrane permeability capacity. The ability of $\mathbf{1 b}$ to penetrate and cross phospholipid membranes, compared to metformin and phenformin, was studied by U-tube experiments, where two aqueous phases are separated by a bulk hydrophobic solvent such as chloroform, to mimick a bilayer membrane (see supporting information). A compound able to penetrate and cross a phospholipid bilayer is able in these conditions to partition into water and chloroform. A concentration of $250 \mu \mathrm{M}$ of biguanide was added to the cis-aqueous side and the concentration of the trans-side was measured after $48 \mathrm{~h}$ and $72 \mathrm{~h}$. Compound $\mathbf{1 b}$ was able to partition rapidly into the chloroform and cross to the trans-aqueous side, while only traces of metformin and phenformin were measured even after $72 \mathrm{~h}$ (Figure 2A). 
A)

\begin{tabular}{c|c|ccc}
\multicolumn{2}{c|}{$48 \mathrm{~h}(\mu \mathrm{M})$} & $72 \mathrm{~h}(\mu \mathrm{M})$ \\
\hline Metformin & \multicolumn{2}{|c|}{-} & \multicolumn{2}{|c}{-} \\
Phenformin & \multicolumn{2}{|c|}{-} & \multicolumn{2}{|c}{} \\
1b & 64.7 & \pm 22.6 & 92.3 & \pm 11.9
\end{tabular}

B)

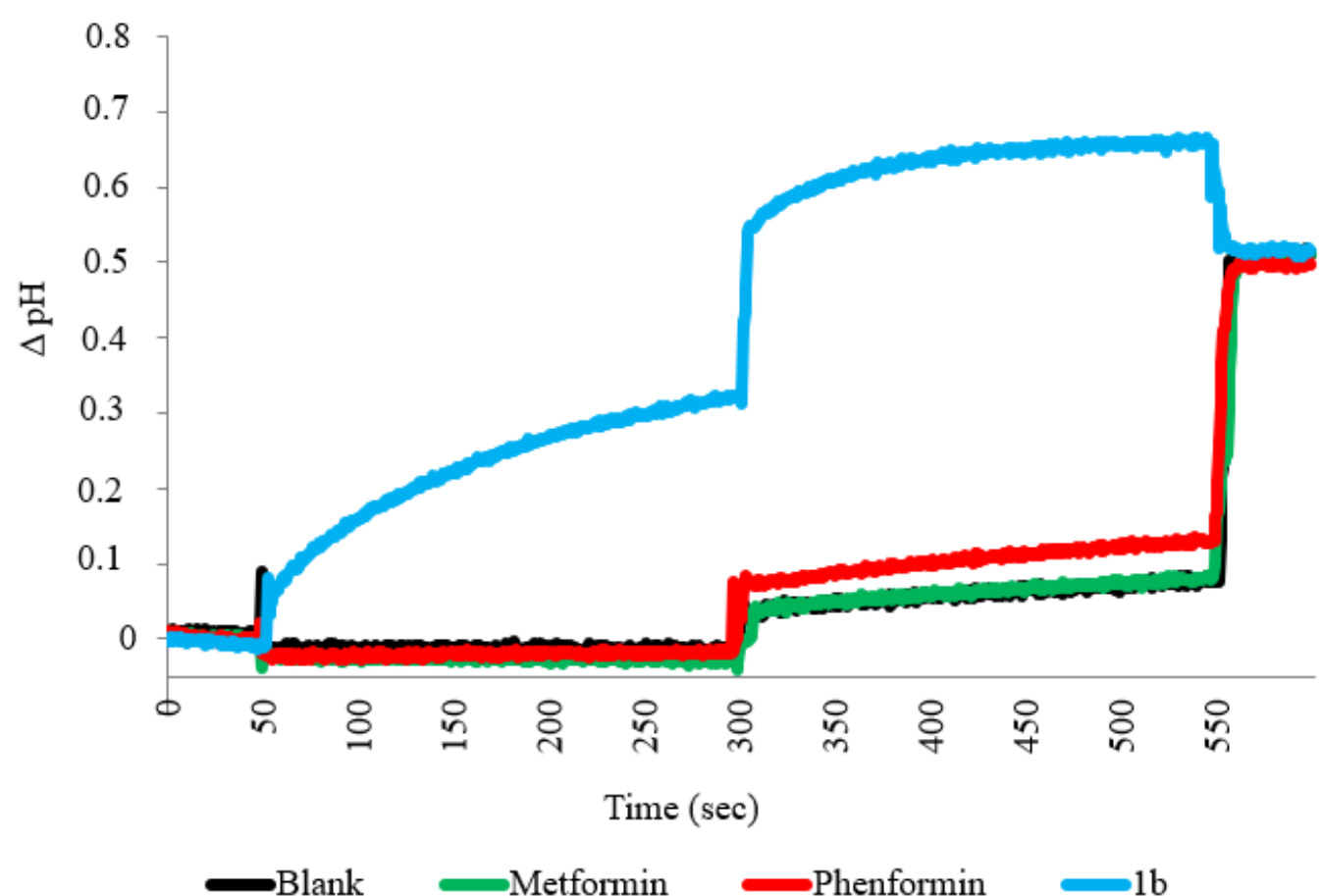


C)

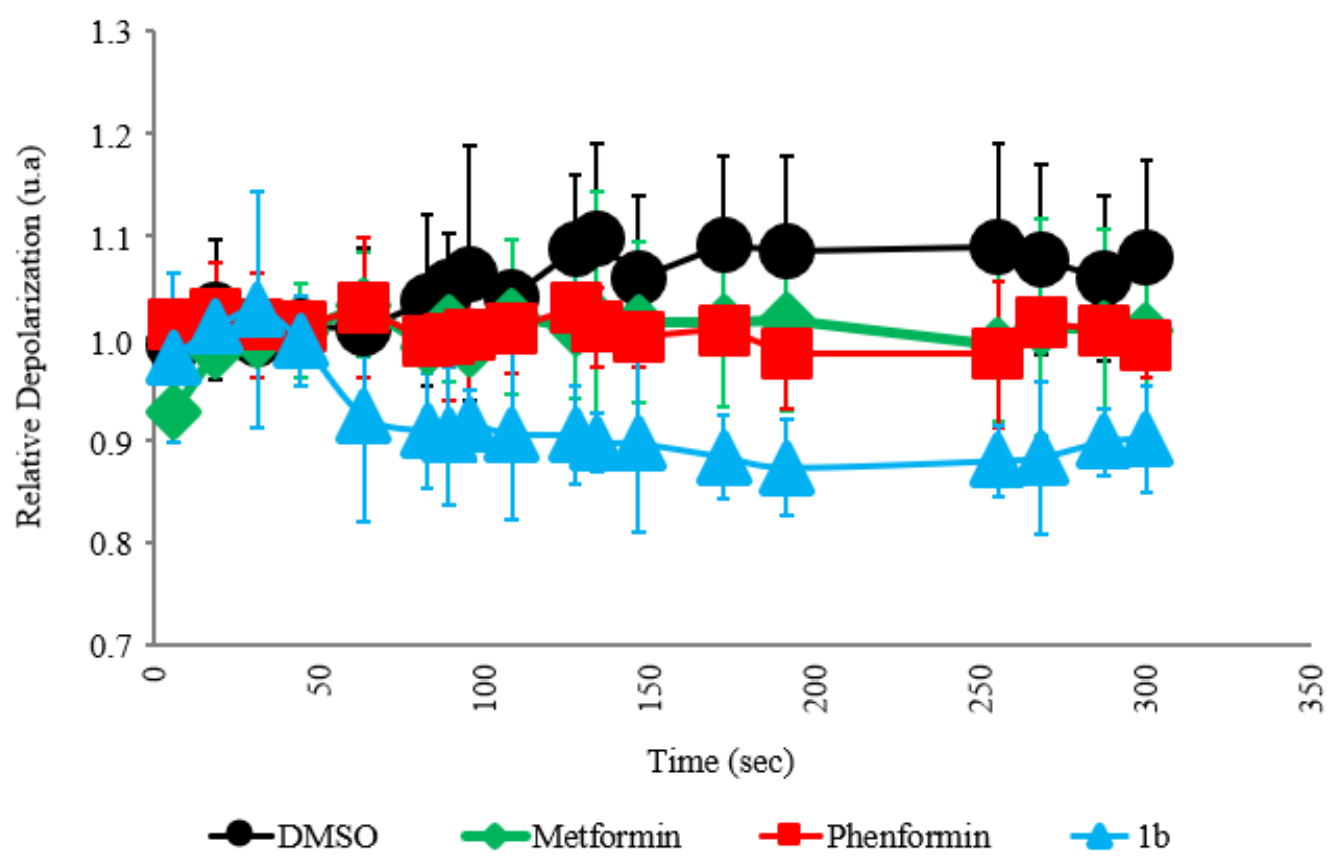

D)
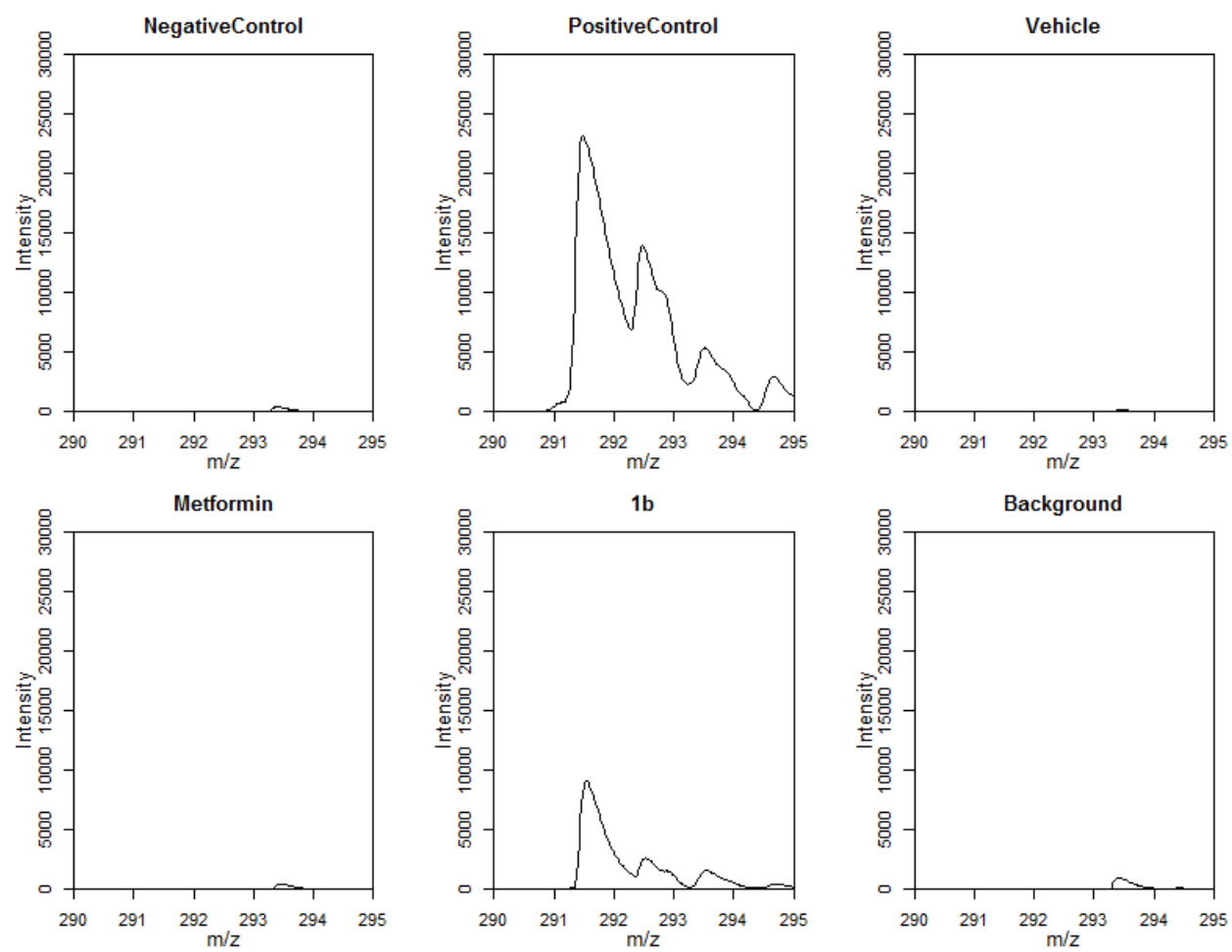
Figure 2: A) Partition of biguanide in a U-tube experiment. Concentration of biguanide on the trans-side of the U-tube at $48 \mathrm{~h}$ and $72 \mathrm{~h}$ at $25^{\circ} \mathrm{C}$, after addition of $250 \mu \mathrm{M}$ of biguanide on the $c i s$-side. B) Variation in the internal pH of HPTS-containing EYPC liposomes. Intravesicular solution: $1 \mathrm{mM}$ HPTS, $10 \mathrm{mM}$ HEPES, and $100 \mathrm{mM} \mathrm{NaCl}$, adjusted to $\mathrm{pH}=7.4$, and extravesicular solution: $10 \mathrm{mM}$ HEPES and $100 \mathrm{mM} \mathrm{NaCl}$, adjusted to $\mathrm{pH}=7.4$. Biguanidiums were injected after $50 \mathrm{sec}$ at $5 \mathrm{mM}$ (50 $\mathrm{mol} \%$ relative to the $10 \mathrm{mM}$ EYPC concentration), a $\mathrm{NaOH}$ pulse was induced at $300 \mathrm{sec}$, and the liposomes were lysed with Triton-X at $550 \mathrm{sec}$. Each curve is the average of three independent measurements. C) Fluorescence of safranin $O$ in the EYPC liposomes. Biguanidiums were injected at $5 \mathrm{mM}$ ( $50 \mathrm{~mol} \%$ relative to the $10 \mathrm{mM} \mathrm{EYPC} \mathrm{concentration)}$ at $50 \mathrm{sec}$. Each curve is the average of three independent measurements.

Mitochondrial penetration of compound $1 \mathrm{~b}$ and metformin. Mitochondrial isolation was performed according to ${ }^{19}$. For each experiment, an anti-HA IP was performed on KP4 cells expressing pMXs-3XHA-EGFP-OMP25 that were treated for 3 hours with $15 \mu \mathrm{M}$ metformin, $15 \mu \mathrm{M}$ compound $\mathbf{1 b}$ or vehicle.

Despite its structural similarity with the PEB-substituted benzimidazolium synthetic transporters and ability to penetrate phospholipid membranes, compound $\mathbf{1 b}$ did not transport chloride across the phospholipid membrane of EYPC-LUVs (See supporting information). As it can be observed in the solid-state structure obtained from chloroform, 1b does not form channel-like supramolecular architectures, but self-assembles into herringbone-shaped interlocked dimers that do not seem to possess chloride transport properties (Figure 1F). 
However, when using EYPC-LUVs containing 8-Hydroxypyrene-1,3,6-trisulfonic acid trisodium salt (HPTS) as $\mathrm{pH}$-sensitive probe, a change of the internal vesicular $\mathrm{pH}$ was observed when compound $\mathbf{1 b}$ was added (Figure 2B). Initially, the pH was neutral and equal in both the extra and intra-vesicular solution. Upon injection of the compound we observed a basification of the internal liposomal solution. This basification was further enhanced with the addition of a base pulse to the external solution at $300 \mathrm{sec}$, indicating either a transport of protons to the extravesicular solution or the transport of hydroxyls to the intravesicular solution. This was also reported for alkylbiguanidium salts and was described as an electrogenic process, i.e. the transmembrane transport of an ion without the balance of the charge through the movement of another ion, which usually results in a charge transfer ${ }^{15}$. Compound $\mathbf{1 b}$, like alkylbiguanidium salts, was not able to transport chloride, so the electroneutral hypothesis of a $\mathrm{H}^{+} / \mathrm{Cl}^{-}$antiport or $\mathrm{OH}^{-} / \mathrm{Cl}^{-}$symport can be rejected and the hypothesis of the electrogenic transport mechanism can be suggested. Metformin and phenformin showed no membrane activity in these experiments.

The transport of $\mathrm{H}^{+} / \mathrm{OH}^{-}$ions across the membrane is an electrogenic mechanism that usually causes the depolarization of the electrochemical gradient across phospholipid membranes. When EYPC liposomes containing intravesicular $\mathrm{K}^{+}$ions are bathing in an extravesicular solution containing $\mathrm{Na}^{+}$ions, a small membrane potential is generated at their membranes and the fluorescence of Safranin O can be used as a membrane potential probe $^{20}$. The addition of $\mathbf{1 b}$ to the external solution of these Safranin-O containing liposomes resulted in a decrease of the Safranin's fluorescence intensity, indicating a depolarization of the membrane (Figure 2C). 
Mitochondrial membrane potential together with the proton gradient are responsible for ATP production ${ }^{21}$ and maintenance of cellular health and function. Compounds able to penetrate mitochondria and alter their membrane potential are usually used as chemotherapeutics. Compound $\mathbf{1 b}$, but not metformin, was able to efficiently penetrate mitochondria after a short incubation of cells with $15 \mu \mathrm{M}$ concentration of each drug (Figure 2D). This indicates that compound $\mathbf{1 b}$ easily diffuses into mitochondria unlike metformin that requires a specialized transporter ${ }^{22}$. These experiments altogether indicate that $\mathbf{1 b}$ is able to penetrate phospholipid and mitochondrial membranes and alter their potential.

\section{Antiproliferative activity in vitro and mechanism of action}

In order to compare the antiproliferative/anticancer activity of compound $\mathbf{1 b}$ to that of the most commonly studied biguanides derivatives metformin and pheformin, we performed growth assays with human PDAC cell lines over 3 days in the presence of various concentrations of these compounds. The results showed that both in KP4 cells (Figure 3A) and in Panc1 cells (Figure 3B), metformin has an $\mathrm{IC}_{50}$ of about $5 \mathrm{mM}$. Phenformin, with an hydrophobic phenyl group, has as lower $\mathrm{IC}_{50}: 51 \mu \mathrm{M}$ in $\mathrm{KP} 4$ and 180 $\mu \mathrm{M}$ in Panc1 cells. Compound $\mathbf{1 b}$ showed much lower $\mathrm{IC}_{50}$ of $6.1 \mu \mathrm{M}$ in $\mathrm{KP} 4$ cells and 15 $\mu \mathrm{M}$ in Panc1 cells, 100-800 fold lower than metformin and 8-12 fold lower than phenformin.

We have recently shown that a short treatment of $24 \mathrm{~h}$ with metformin of the mouse PDAC cell line AH375 grown adherent in 2D decreases the ability of this cell line to 
subsequently grow as spheres in suspension ${ }^{23}$. Here again compound $\mathbf{1 b}$ show a better biological activity than metformin (Figure 3C) as it decreases by $75 \%$ the number of AH375 spheres when treated for $24 \mathrm{~h}$ with $5 \mu \mathrm{M}$ of it, while metformin at $1 \mathrm{mM}$ results in a less marked decrease of 50\%. In agreement with compound $\mathbf{1 b}$ higher ability to inhibit cancer cells, we observed that compound $\mathbf{1 b}$ induces a significant increase $(\sim 20 \%)$ of the fraction of dead KP4 cells (Figure 3G) treated at $15 \mu \mathrm{M}$ for $24 \mathrm{~h}$ (measured by trypan blue exclusion) while metformin $(5 \mathrm{mM})$ and phenformin $(50 \mu \mathrm{M})$ had no significant effects. In contrast with its effect in PDAC cells (KP4), compound 1b did not increase the fraction of dead cells in normal immortalized non-tumorigenic pancreatic human cells HPNE hTERT in the same conditions (Figure 3H), suggesting selectivity towards cancer cells.

To better characterize the molecular mechanism of action of compound $\mathbf{1 b}$ we measured the $\mathrm{NAD}^{+} / \mathrm{NADH}$ ratio as it was shown that metformin decreases this ratio through inhibition of mitochondrial respiration ${ }^{24}$. In agreement, both in pancreatic cancer PSN1 cells (Figure 3D) and KP4 cells (Figure 3E) compound 1b at $15 \mu \mathrm{M}$ decreased $\mathrm{NAD}^{+} / \mathrm{NADH}$ ratio by $25 \%$ and $40 \%$ respectively, as did phenformin $(50 \mu \mathrm{M})$ and metformin $(5 \mathrm{mM})$. These results suggest that, as metformin and phenformin do, compound $\mathbf{1 b}$ is able to inhibit mitochondrial respiration, but at a much lower concentration. However, as it is broadly reported for metformin and phenformin ${ }^{25}$, compound $\mathbf{1 b}$ does not activate phosphorylation of AMPK on T172 and that of the AMPK-target ACC (acetyl-CoA carboxilase (Figure 3F).

Next, we used the Seahorse analyser to quantify the ability of compound $\mathbf{1 b}$ to affect oxygen consumption rate (OCR) in KP4 cells. We were able to determine that compound 1b inhibited OCR at $15 \mu \mathrm{M}$, similarly to metformin at $5 \mathrm{mM}$ (Figure 3I). Inhibition of 
OCR by metformin was simultaneously associated with an increase of the ECAR (roughly: glycolysis), which was also observed with compound 1b (Figure 3J). These data suggest that the anticancer activity of compound $\mathbf{1 b}$ is due at least in part to the inhibition of mitochondrial respiration, similar to metformin, but at much lower concentration. To further confirm this idea we visualized mitochondria in cells treated with biguanides. Both compound $\mathbf{1 b}$ and metformin led to a lost of the filamentous mitochondrial network but compound $\mathbf{1 b}$ had a bigger impact in mitochondrial morphology leading to a punctuated pattern typical of very dysfunctional mitochondria (Figure 3K-M). Together these data show that compound $\mathbf{1 b}$ functions as metformin or phenformin but with a much higher activity, presumably due to its intrinsic chemical characteristics and membrane activity. 

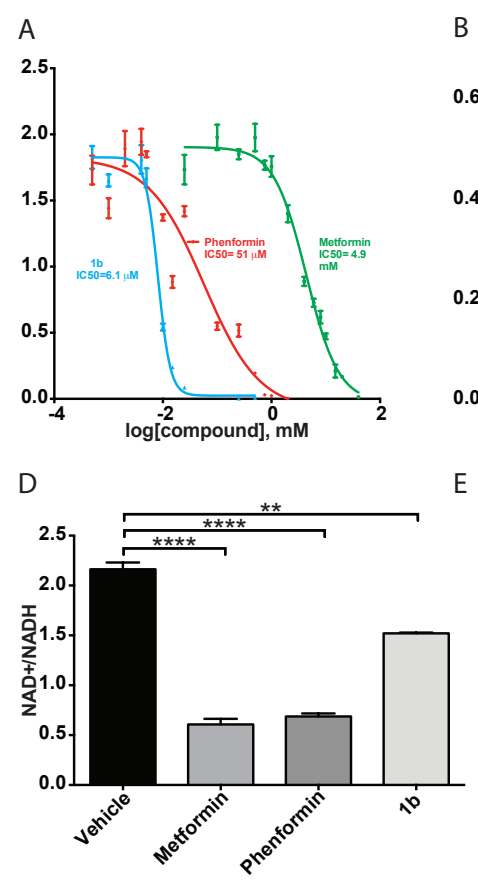

G

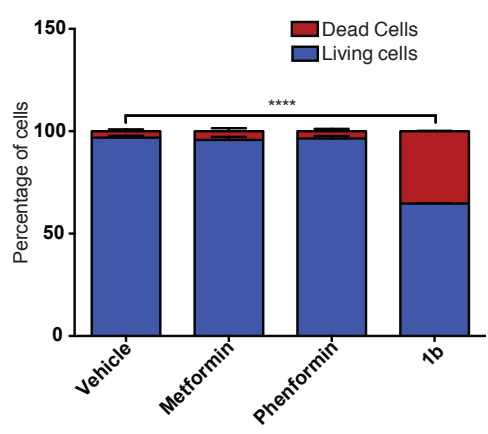

I

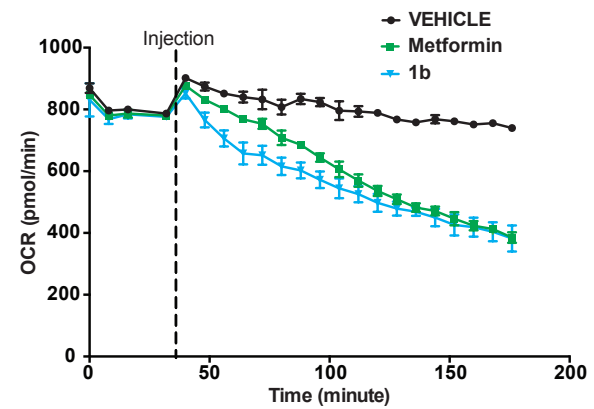

B

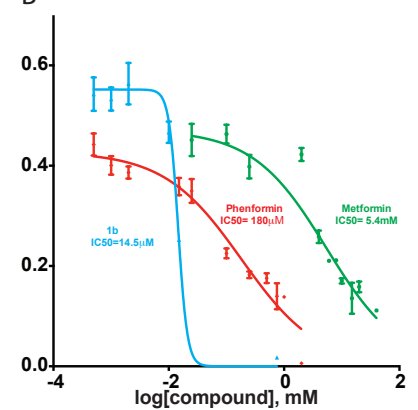

$E$

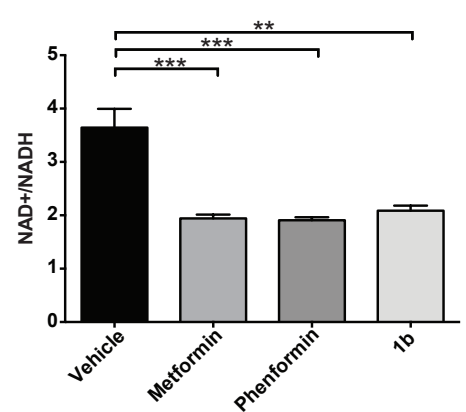

C

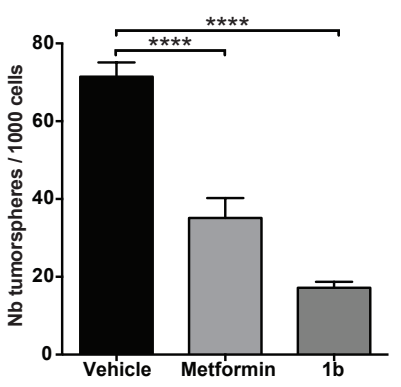

$\mathrm{F}$

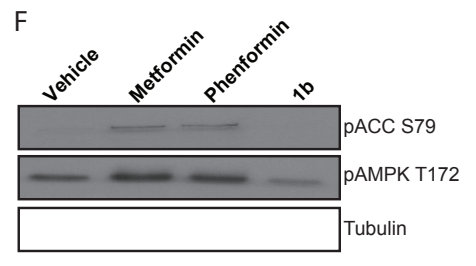

J
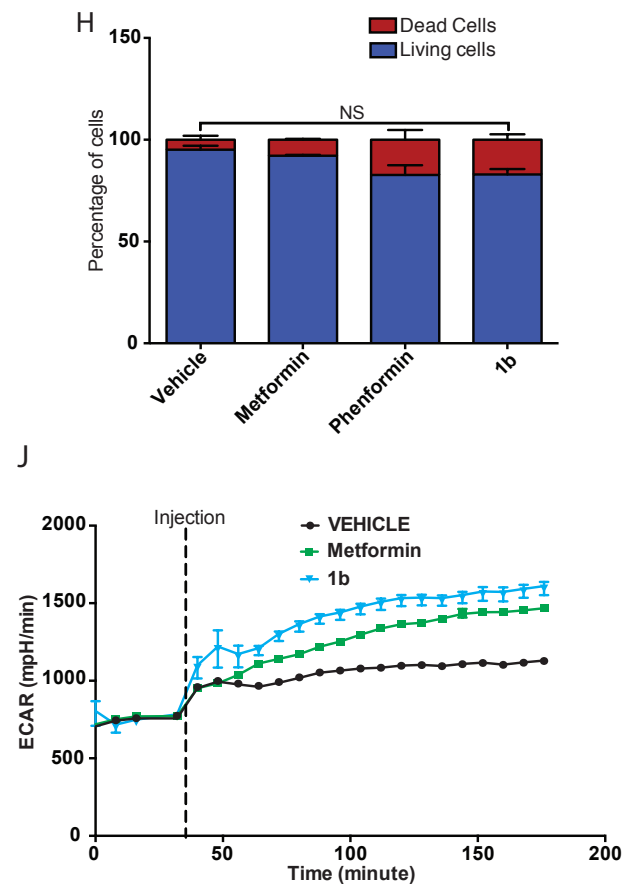


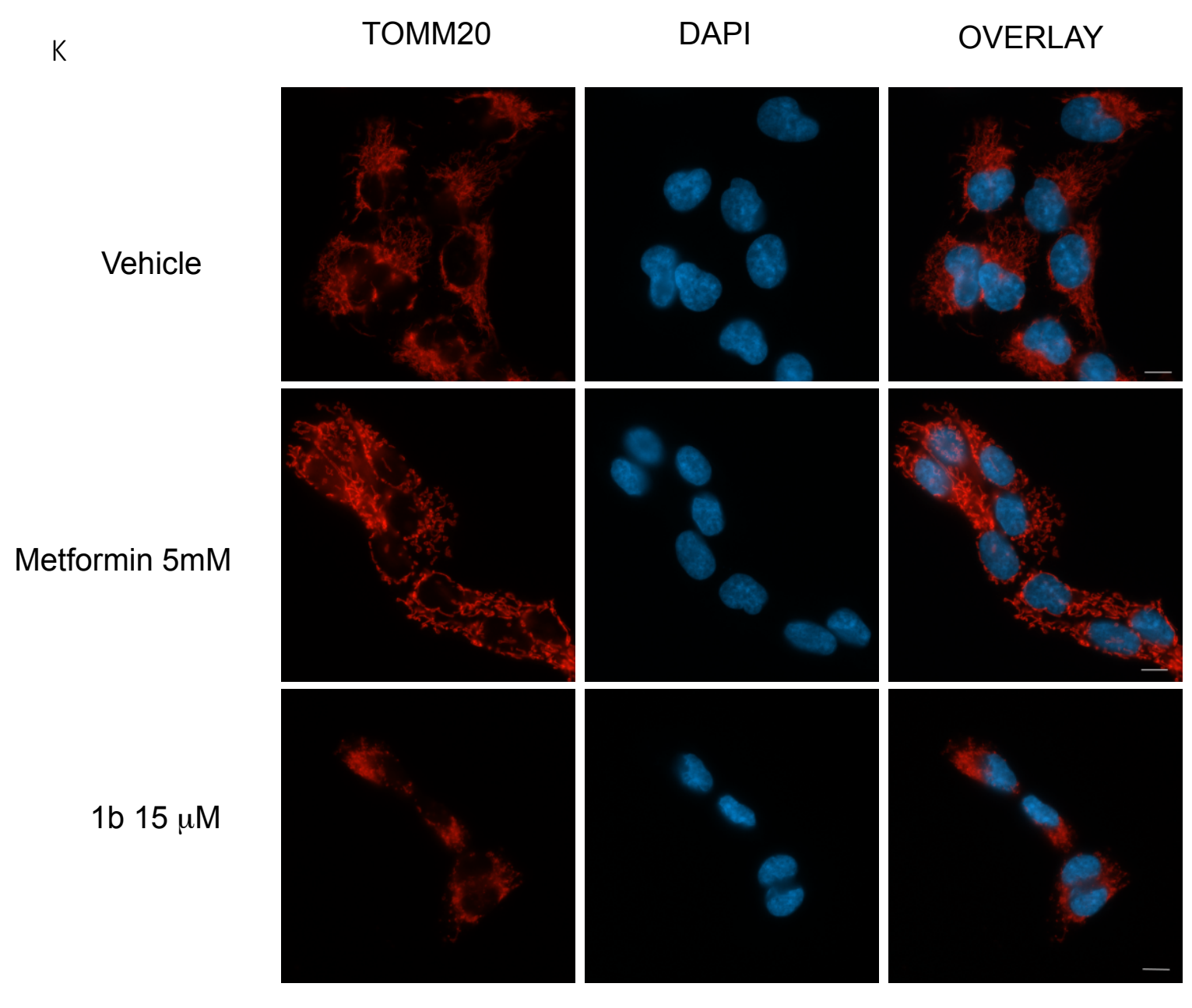

Mitochondrial Ultrastructure

$L$

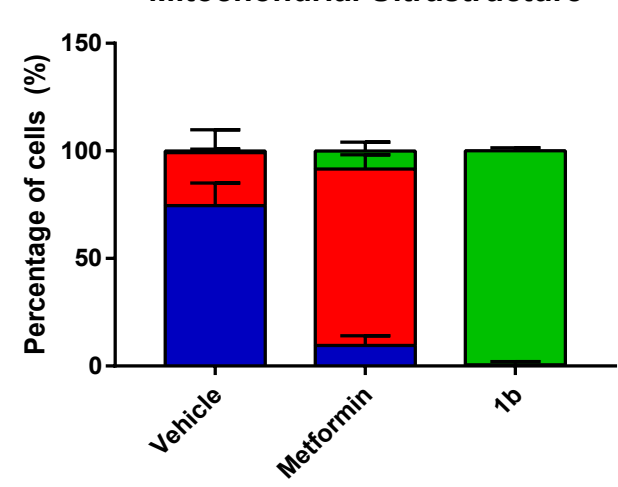

$\begin{array}{crrrr}\text { Punctuated } \square & 0.8 & 8.4 & 99.4 & \mathrm{P}=1.1102 \mathrm{e}-16 \\ \text { Fragmented } \square & 24.6 & 82.0 & 0.6 & \mathrm{P}=1.4184 \mathrm{e}-11 \\ \text { Filamentous } \square & 74.6 & 9.6 & 0.0 & \mathrm{P}=6.1755 \mathrm{e}-12\end{array}$




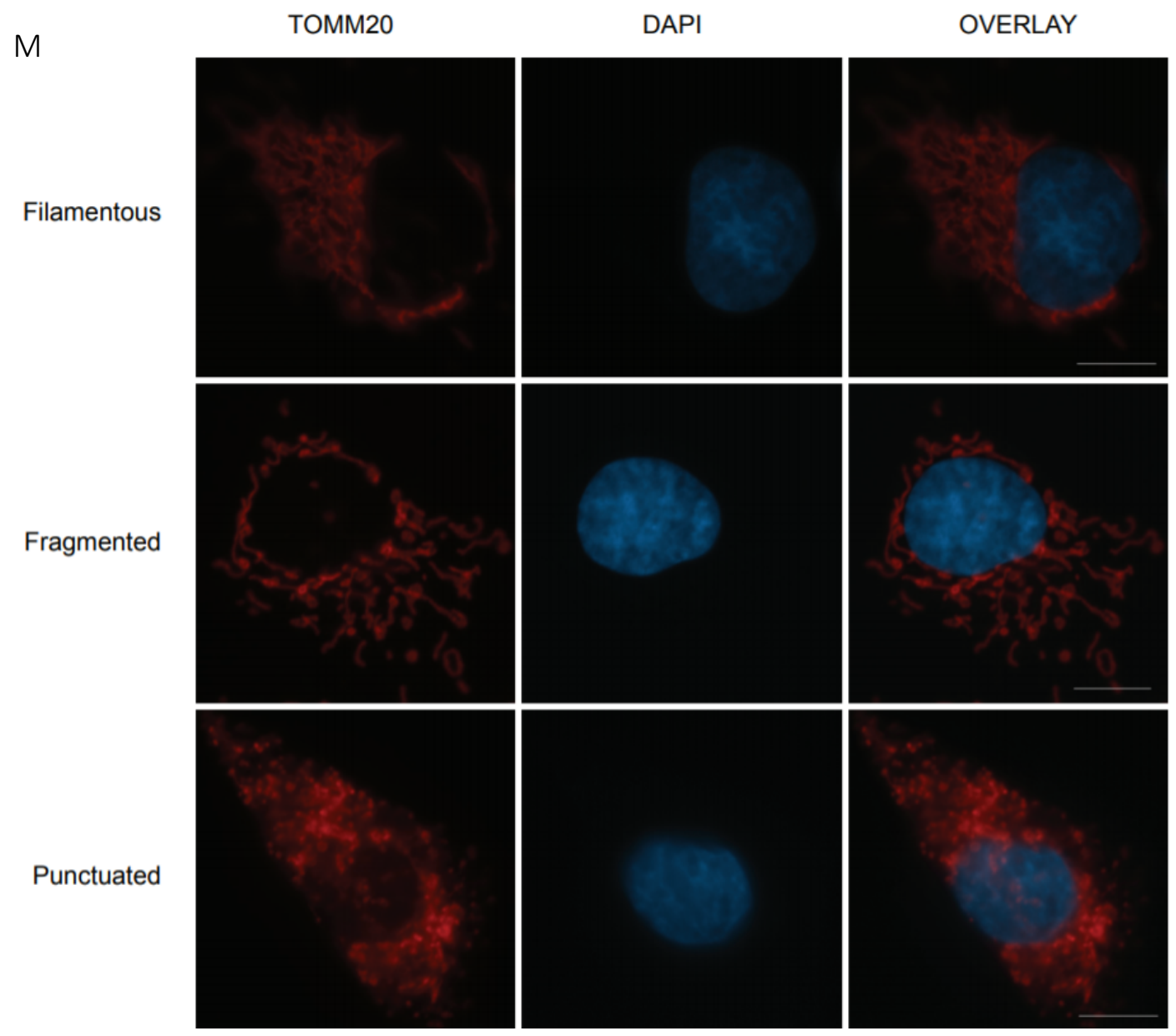

Figure 3. A) $\mathrm{IC}_{50}$ of metformin, phenformin and compound $1 \mathrm{~b}$ performed in vitro over 3 days on $\mathrm{KP} 4$ cells. $\mathrm{B}) \mathrm{IC}_{50}$ of metformin, phenformin and compound $1 \mathrm{~b}$ performed in vitro over 3 days on Panc1 cells. C) Effect of 24 h treatment with metformin $(1 \mathrm{mM})$ or compound $1 \mathrm{~b}(5 \mu \mathrm{M})$ on the formation of tumorspheres in AH375 cells grown in suspension (mouse pancreatic ductal adenocarcinoma). **** $\mathrm{p} \leq 0.0001$ (ANOVA). D) Effect of treatment for $6 \mathrm{~h}$ of PSN1 cells with metformin (10 mM), phenformin $(100 \mu M)$ or compound $1 b(25 \mu M)$ on $\mathrm{NAD}^{+} / \mathrm{NADH}$ ratio. ** $\mathrm{p} \leq 0.01, * * * * \mathrm{p} \leq 0.0001$ (ANOVA). E) Effect of treatment for $\mathbf{1 8 h}$ of KP4 cells with metformin $(5 \mathrm{mM})$, phenformin $(50 \mu M)$ or compound $1 b(15 \mu M)$ on NAD+/NADH ratio. ${ }^{* *} \mathrm{p} \leq 0.01, * * * \mathrm{p} \leq 0.001$ (ANOVA). F) Effect of treatment for $24 \mathrm{~h}$ of KP4 cells 
with metformin $(5 \mathrm{mM})$, phenformin $(50 \mu \mathrm{M})$ or compound $1 \mathrm{~b}(15 \mu \mathrm{M})$ on phosphorylation level of AMPK T172 and ACC S79. G) Effect of treatment for 24h of KP4 cells with metformin $(5 \mathrm{mM})$, phenformin $(50 \mu \mathrm{M})$ or compound $1 \mathrm{~b}(15 \mu \mathrm{M})$ on cell viability. H) Effect of treatment for $24 \mathrm{~h}$ of HPNE hTERT cells with metformin (5 $\mathrm{mM})$, phenformin $(50 \mu \mathrm{M})$ or compound $1 \mathrm{~b}(15 \mu \mathrm{M})$ on cell viability. $* * * *$ $\mathrm{p} \leq 0.0001$, NS: not significative (ANOVA). I) Effect of treatment of KP4 cells with metformin $(10 \mathrm{mM})$ or compound $1 \mathrm{~b}(15 \mu \mathrm{M})$ on oxygen consumption rate (OCR) measured by Seahorse analysis. (J) Effect of treatment of KP4 cells with metformin (10 $\mathrm{mM})$ or compound $1 \mathrm{~b}(15 \mu \mathrm{M})$ on ECAR (extracellular acidification rate) measured by Seahorse analysis. K) Mitochondrial morphology in KP-4 cells 24 h following the indicated treatments as visualised by anti-TOMM20 immunofluorescence. Scale bar $=10 \mu \mathrm{M}$. L) Quantification of the percentage of cells exhibiting filamentous, fragmented or punctuated mitochondria following indicated treatments. The data represents the mean of 2 biological replicates and for each replicate three counts of 50 cells were done. $n=300$ cells per treatment. Data was analyzed with one way Anova followed by Tukey HSD test. M) Mitochondrial morphology as visualised by immunofluorescence with anti-TOMM20 antibody. The filamentous structure is from KP-4 cells treated with vehicle, the fragmented structure is from metformin KP-4 cells treated with metformin, and the punctuated structure is from KP-4 cells treated with $\mathbf{1 b}$. Scale bar $=10 \mu \mathrm{m}$. 


\section{Antiproliferative activity in vivo}

To determine whether coumpound $\mathbf{1 b}$ is also superior to phenformin in vivo, mice were engrafted with subcutaneous KP4 PDAC cells tumors. After randomization, mice received either phenformin ( $\mathrm{n}=6$ mice, 2 tumors per mouse), compound $\mathbf{1 b}(\mathrm{n}=17$ mice, 2 tumors per mouse) both at $(50 \mathrm{mg} / \mathrm{kg} / \mathrm{d}$ IP, $5 \mathrm{~d} /$ week) or vehicle ( $\mathrm{n}=10$ mice, 2 tumors per mouse). Compound 1b significantly reduced tumor volume (Figure 4) and mice survival time, while phenformin administred at the same dose had only modest or nonsignificant effects. Together our data show that in vivo, compound $\mathbf{1 b}$ is well tolerated and more effective than the most active biguanide used curently in human, phenformin.

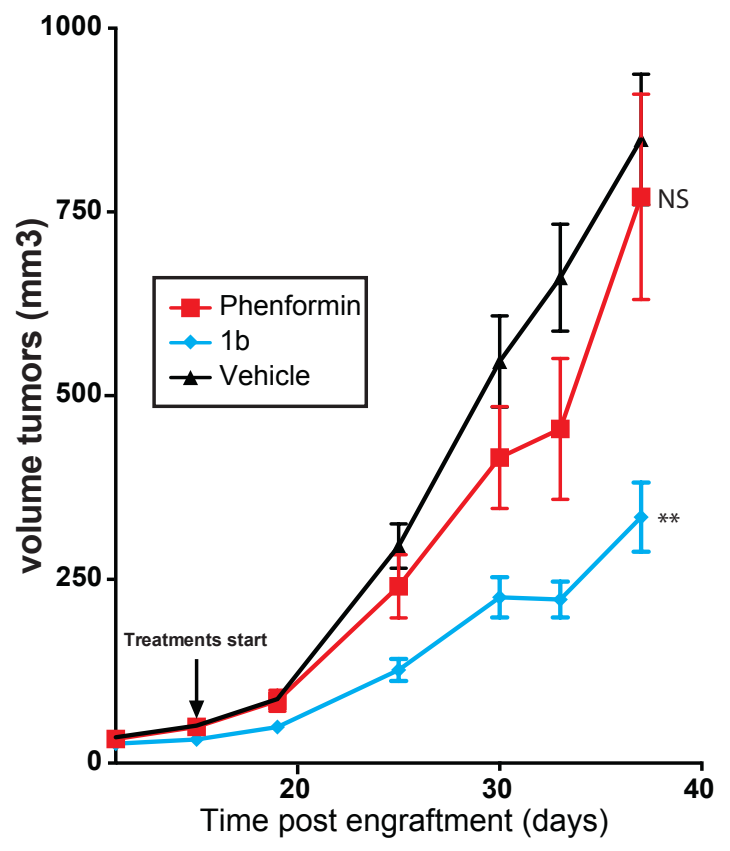

Figure 4. Progression of the volume of KP4 cells sub-cutaneous xenografts performed in nude mice over 37 days. Treatments with phenformin or compound $\mathbf{1 b}$ (both at $50 \mathrm{mg} / \mathrm{kg} / \mathrm{d}, 5$ days a week) or vehicle were started 11 days post engrafment. ** $\mathrm{p} \leq 0.01$, NS: not significative (ANOVA). 


\section{Conclusion}

In conclusion, by screening a small library of phenylethynylbenzyl-modified metformin analogs we identified a compound able to penetrate mitochondrial membranes, 1000-fold more active than metformin. Compound 1b selectively induces the death of PDAC cells (KP4), at least in part by the inhibition of mitochondrial respiration, in a similar way to metformin but at much lower concentration. Compound $\mathbf{1 b}$ is more active than metformin and phenformin to inhibit the proliferation of PDAC cells in vivo, as it significantly inhibitis the growth of xenografts and increases mice survival time. We demonstrate herein that the anticancerous properties of biguanides can be improved by chemical modifications. Thenew PEB-Biguanidium compound constitutes a first-class lead compound that can be used to target mitochondria in pancreatic cancer and potentially other cancers.

\section{Author Contributions}

The manuscript was written through contributions of all authors. All authors have given approval to the final version of the manuscript. A.H. prepared figures $1 \mathrm{~A}-\mathrm{F}$, figures $2 \mathrm{~A}-$ C, M.P. prepared figures 3 A-F, I-J and figure 4, M.-C.R. prepared figures 3 G-M and A.D. prepared figure 2D. All authors declare no conflict of interest.

\section{Funding Sources}

Canadian Institutes of Health Research (CIHR), Canadian Cancer Society (CCS), Natural Sciences and Engineering Research Council of Canada (NSERC), Fonds Québécois de la 
Recherche sur la Nature et les Technologies (FRQ-NT), and the Fonds Marguerite Ruel pour la Recherché sur le Cancer - Université de Montréal.

\section{Acknowledgments}

We gratefully acknowledge the Canadian Institutes of Health Research (CIHR), Canadian

Cancer Society (CCS), the Cancer Research Society, Natural Sciences and Engineering Research Council of Canada (NSERC), Fonds Québécois de la Recherche sur la Nature et les Technologies (FRQ-NT), and Fonds Marguerite Ruel pour la Recherché sur le Cancer - Université de Montréal for financial support. G.F. is supported by the CIBC chair for breast cancer research at the CRCHUM.

\section{References}

1. Barone, B. B.; Yeh, H. C.; Snyder, C. F.; Peairs, K. S.; Stein, K. B.; Derr, R. L.; Wolff, A. C.; Brancati, F. L., JAMA 2008, 300 (23), 2754-64.

2. Giovannucci, E.; Harlan, D. M.; Archer, M. C.; Bergenstal, R. M.; Gapstur, S. M.; Habel, L. A.; Pollak, M.; Regensteiner, J. G.; Yee, D., CA Cancer J Clin 2010, 60 (4), 207-21.

3. Ben Sahra, I.; Le Marchand-Brustel, Y.; Tanti, J. F.; Bost, F., Mol Cancer Ther 2010, 9 (5), 1092-9.

4. Kordes, S.; Pollak, M. N.; Zwinderman, A. H.; Mathôt, R. A.; Weterman, M. J.; Beeker, A.; Punt, C. J.; Richel, D. J.; Wilmink, J. W., The Lancet Oncology 2015, $16(7), 839-847$.

5. Coyle, C.; Cafferty, F. H.; Vale, C.; Langley, R. E., Ann Oncol 2016, 27 (12), 21842195.

6. Bhaw-Luximon, A.; Jhurry, D., J Cancer Res Clin Oncol 2016, 142 (10), 2159-71. 
7. Wheaton, W. W.; Weinberg, S. E.; Hamanaka, R. B.; Soberanes, S.; Sullivan, L. B.; Anso, E.; Glasauer, A.; Dufour, E.; Mutlu, G. M.; Budigner, G. S.; Chandel, N. S., Elife 2014, 3, e02242.

8. $\quad$ Owen, M. R.; Doran, E.; Halestrap, A. P., Biochemical Journal 2000, 348 (3), 607614.

9. Chandel, N. S.; Avizonis, D.; Reczek, C. R.; Weinberg, S. E.; Menz, S.; Neuhaus, R.; Christian, S.; Haegebarth, A.; Algire, C.; Pollak, M., Cell metabolism 2016, 23 (4), 569-570.

10. Narise, K.; Okuda, K.; Enomoto, Y.; Hirayama, T.; Nagasawa, H., Drug Des Devel Ther 2014, 8, 701-717.

11. Boukalova, S.; Stursa, J.; Werner, L.; Ezrova, Z.; Cerny, J.; Bezawork-Geleta, A.; Pecinova, A.; Dong, L.; Drahota, Z.; Neuzil, J., Mol Cancer Ther 2016, 15 (12), 2875-2886.

12. Andrzejewski, S.; Gravel, S. P.; Pollak, M.; St-Pierre, J., Cancer Metab 2014, 2, 12.

13. Elie, C. R.; Hebert, A.; Charbonneau, M.; Haiun, A.; Schmitzer, A. R., Org Biomol Chem 2013, 11 (6), 923-928.

14. Vidal, M.; Elie, C. R.; Campbell, S.; Claing, A.; Schmitzer, A. R., Med Chem Comm 2014, 5 (4), 436-440.

15. Hébert, A.; Parisotto, M.; Ferbeyre, G.; Schmitzer, A. R., Supramolecular Chemistry 2018, 31 (3), 127-139.

16. Vidal, M.; Elie, C.-R.; Campbell, S.; Claing, A.; Schmitzer, A. R., Med. Chem. Commun. 2014, 5 (4), 436-440.

17. National Center for Biotechnology Information. PubChem Database. Metformin, C., https://pubchem.ncbi.nlm.nih.gov/compound/Metformin (accessed on July 19, 2019).

18. National Center for Biotechnology Information. PubChem Database. Phenformin, C., https://pubchem.ncbi.nlm.nih.gov/compound/Phenformin (accessed on July 19, 2019).

19. Chen, W. W.; Freinkman, E.; Wang, T.; Birsoy, K.; Sabatini, D. M., Cell 2016, 166 (5), 1324-1337 e11. 
20. Zha, H. Y.; Shen, B.; Yau, K. H.; Li, S. T.; Yao, X. Q.; Yang, D., Org Biomol Chem 2014, 12 (41), 8174-8179.

21. Zorova, L. D.; Popkov, V. A.; Plotnikov, E. Y.; Silachev, D. N.; Pevzner, I. B.; Jankauskas, S. S.; Babenko, V. A.; Zorov, S. D.; Balakireva, A. V.; Juhaszova, M.; Sollott, S. J.; Zorov, D. B., Anal Biochem 2018, 552, 50-59.

22. Kimura, N.; Okuda, M.; Inui, K.-i., Pharmaceutical Research 2005, 22 (2), 255 259.

23. Deschenes-Simard, X.; Parisotto, M.; Rowell, M. C.; Le Calve, B.; Igelmann, S.; Moineau-Vallee, K.; Saint-Germain, E.; Kalegari, P.; Bourdeau, V.; Kottakis, F.; Bardeesy, N.; Ferbeyre, G., Aging Cell 2019, e12889.

24. Birsoy, K.; Possemato, R.; Lorbeer, F. K.; Bayraktar, E. C.; Thiru, P.; Yucel, B.; Wang, T.; Chen, W. W.; Clish, C. B.; Sabatini, D. M., Nature 2014, 508 (7494), 108-112.

25. Hardie, D. G., Gastroenterology 2006, 131 (3), 973; author reply 974-975. 